\title{
p2 $7^{\mathrm{KIP} 1}$ and PTEN cooperate in myeloproliferative neoplasm tumor suppression in mice
}

\author{
Jingchen Shao ${ }^{1,2}$, Susann Li $i^{1,2}$, Lars Palmqvist ${ }^{1,2}$, Linda Fogelstrand ${ }^{1,2}$, Stella Y. Wei ${ }^{1,3}$, Kiran Busayavalasa ${ }^{4}$, \\ Kui Liu ${ }^{4}$ and Viktor M. Liu ${ }^{1,2^{*}}$ (D)
}

\begin{abstract}
PTEN acts as a phosphatase for PIP3 and negatively regulates the PI3K/AKT pathway, and p2 $27^{\text {KIP1 }}$ is a cyclin-dependent kinase inhibitor that regulates the G1 to S-phase transition by binding to and regulating the activity of cyclin-dependent kinases. Genetic alterations of PTEN or CDKN1B $\left(\mathrm{p} 27^{\mathrm{KIP} 1}\right)$ are common in hematological malignancies. To better understand how mutations in these two genes might cooperate in leukemogenesis, we inactivated both genes in the hematological compartment in mice. Here, we show that the combined inactivation of Pten and C $d k n 1 b$ results in a more severe myeloproliferative neoplasm phenotype associated with lower hemoglobin, enlarged spleen and liver, and shorter lifespan compared to inactivation of Pten alone. More severe anemia and increased myeloid infiltration and destruction of the spleen contributed to the earlier death of these mice, and elevated p-AKT, cyclin D1, and cyclin D3 might contribute to the development of this phenotype. In conclusion, PTEN and p2 $7^{\mathrm{KI} 1}$ cooperate in tumor suppression in the hematological compartment.
\end{abstract}

Keywords: PTEN, p27 KIP1 , Myeloproliferative neoplasms

\section{Background}

PTEN (phosphatase and tension homolog deleted on chromosome 10) is a tumor suppressor gene located on chromosome 10q23 and is one of the most commonly mutated or deleted genes in human cancers, including acute lymphoblastic leukemia, juvenile myelomonocytic leukemia, and non-Hodgkin's lymphoma [1, 2]. PTEN acts as a phosphatase for phosphatidylinositol-3,4,5trisphosphate (PIP3) and negatively regulates the phosphatidylinositol 3-kinase (PI3K)/AKT pathway [3]. The $C D K N 1 B$ gene encodes $\mathrm{p} 27^{\mathrm{KIP} 1}$, which belongs to the Cip/Kip family of cyclin-dependent kinase inhibitors. $\mathrm{p} 27^{\mathrm{KIP} 1}$ is a key regulator of the G1 to S-phase transition by inhibiting cyclinD1/CDK4 and cyclinE/CDK2 complexes [4]. Deletions and other cytogenetic aberrations involving $C D K N 1 B$ have been reported in a variety of

\footnotetext{
*Correspondence: meng.liu@gu.se

${ }^{2}$ Laboratory of Clinical Chemistry, Sahlgrenska University Hospital, Gothenburg, Sweden

Full list of author information is available at the end of the article
}

leukemias [5-7]. In addition, $C D K N 1 B$ expression can be a useful prognostic molecular marker for acute myeloid leukemia, where low CDKN1B expression is associated with high proliferation and, therefore, with a favorable response to chemotherapy [6]. Inactivation of the tumorsuppressor gene PTEN and lack of CDKN1B expression have been detected in some kinds of cancer, including most advanced prostate cancers and lymphomas $[8,9]$. It has been shown that the combined loss of PTEN and $\mathrm{p} 27^{\mathrm{KIP} 1}$ is associated with tumor cell proliferation and increased risk of recurrent disease in localized prostate cancer [10]. Loss of PTEN expression is more frequent in anaplastic large-cell lymphoma, which strongly correlates with the loss of $C D K N 1 B$ expression [9].

Targeted disruption of the murine $C d k n 1 b$ gene causes a gene dose-dependent increase in animal size without other gross morphologic abnormalities [11], and deletion of Pten in the hematopoietic compartment in mice promotes excessive proliferation of leukemogenic stem cells resulting in the development of myeloproliferative 
neoplasm (MPN) followed by acute leukemia [12]. In mice, concomitant inactivation of Pten and Cdkn1b accelerates spontaneous neoplastic transformation of prostate cancer [8]. In order to better understand the relation and clinical relevance of these two genes in the pathogenesis of hematological malignancies, we used Cre recombinase to simultaneously inactivate Pten and $C d k n 1 b$ in the hematopoietic compartment.

\section{Results and discussion}

To determine the impact of combined deficiency of PTEN and $\mathrm{p} 27^{\mathrm{KIP} 1}$ in the hematopoietic compartment, we injected pI-pC into PCM, PM, CM and Ctrl mice. Consistent with previous studies [13], all $P M$ mice died from MPN by 98 days after $\mathrm{pI}-\mathrm{pC}$ injections (median survival 62 days), whereas $C M$ and $C t r l$ mice lived much longer and no MPN phenotype was observed in $C M$ mice. However, the maximum survival of $P C M$ mice was only 30 days (median 24 days; $p<0.001$ versus PM; Fig. 1a). Two weeks after $\mathrm{pI}-\mathrm{pC}$ injections, white blood cell counts were $20.8 \times 10^{9}$ cells $/ \mathrm{L}$ in $P C M$ mice compared with mean counts of $18.3 \times 10^{9}, 13.9 \times 10^{9}$ and $13.6 \times 10^{9}$ cells $/ \mathrm{L}$ for $P M, C M$ and $C t r l$ mice, respectively (Fig. 1b). However, no morphological changes and no increase in the amounts of immature cells, including myeloblasts, could be detected in the blood and bone marrow in PCM mice compared with the other three groups (Fig. 1c, e). More severe anemia and more architectural disruption of the spleen were observed in PCM mice (Fig. 1d, e).

Spleen and liver weights in PCM mice increased by 2.3-5.6 and 1.2-2.4-fold, respectively, compared with $P M, C M$ and Ctrl mice (Fig. 2a, b). Fluorescence-activated cell sorting analysis showed an increased proportion of $\mathrm{CD} 1 \mathrm{~b}+/ \mathrm{Gr} 1+$ and LSK [Lineage-negative (lin-), Sca-1+, c-Kit+] cells in the spleen of PCM mice compared to $P M, C M$ and $C t r l$ mice $(p<0.05$; Fig. 2c). Splenocytes from $P C M$ mice produced more colonies compared with the other three groups (Fig. 2d). In bone marrow, there were no differences in the percentage of LSK cells (Fig. 2e). No increased colony formation in $P C M$ mice was observed compared to $P M$ mice when replated, and both groups had more colonies than the $\mathrm{Ctrl}$ mice when replated (Fig. 2f). Taken together, the phenotype in PCM mice is severe MPN rather than acute leukemia based on the criteria for classification of hematopoietic neoplasms in mice [14]. More severe anemia and increased myeloid infiltration and destruction of the spleen likely contributed to the earlier death of $P C M$ mice compared with $P M$ mice.

We performed Western blot analysis to determine the knock-out efficiency and the consequences of inactivating PTEN and p27 $7^{\mathrm{KIP} 1}$ on downstream molecules. Deficiency of PTEN or $\mathrm{p} 27^{\mathrm{KIP} 1}$ was observed in the respective knock-out mice (Fig. 2g). It has been shown that PTEN activity leads to the induction of $\mathrm{p} 27^{\mathrm{KIP} 1}$, which in turn can negatively regulate the transition through the cell cycle [15]. However, the association between PTEN and p2 ${ }^{\mathrm{KIP} 1}$ might be different in different kinds of tissues. A lack of convincing correlation between PTEN and p27 KIP1 has been reported for ovarian carcinomas, indicating the possible existence of $\mathrm{p} 27^{\mathrm{KIP} 1}$-independent pathways downstream of PTEN [16]. In our study, we found that expression of $\mathrm{p} 27^{\mathrm{KIP} 1}$ was reduced in the splenocytes of $P M$ mice. $P C M$ mice had higher phosphorylated AKT compared to $P M, C M$, and Ctrl mice (Fig. $2 \mathrm{~g}$ ), and cyclin D1 and cyclin D3 expression levels were elevated in $P C M$ and $P M$ mice. However, the levels of phosphorylated ERK1/2 were similar in all groups of mice. Previous studies showed the synergistic activity of PI3K/mTOR and JAK2 signaling pathway in the myeloproliferative neoplasms $[17,18]$, therefore it will be interesting to study the JAK2 activity in PTEN and p2 $7^{\mathrm{KIP} 1}$ knockout mice model.

In conclusion, our results show that PTEN deficiency can promote tumor progression by a decrease in $\mathrm{p} 27^{\mathrm{KIP} 1}$ levels in the hematological compartment and that PTEN and $\mathrm{p} 27^{\mathrm{KIP} 1}$ have a cooperative role in leukemia suppression. In addition, our results show that elevated phosphorylated AKT, cyclin D1, and cyclin D3 might play an important role in the progression of the severe MPN phenotype.

\section{Methods}

\section{Animal procedures}

Mice with conditional $P t e n^{\mathrm{fl} / \mathrm{fl}}$ alleles (designated $P$ ) with a mixed genomic background of 129S4/SvJae and C57BL/6J were bred with $C d k n 1 b^{\mathrm{t} / / \mathrm{fl}}$ mice (designated $C$ ) to generate $P C$ mice. $P C$ mice were bred with mice harboring the interferon (IFN)-inducible Mx1-Cre transgene (designated $M)$ to generate $P C M\left(P_{t e n}{ }^{\mathrm{f} / f \mathrm{l}} C d k n 1 b^{\mathrm{f} / \mathrm{fl}}\right.$ Mx1-Cre), PM (Pten $\left.{ }^{\mathrm{f} / \mathrm{fl}} \mathrm{Mx1}-\mathrm{Cre}\right)$, and $C M\left(C d k n 1 b^{\mathrm{f} /}\right.$

${ }^{\mathrm{fl}} \mathrm{Mx1}$-Cre) mice. Mice without Mx1-Cre were used as healthy controls (designated $\mathrm{Ctrl}$ ).

The mice were housed under controlled environmental conditions with free access to water and food. Illumination was on between 0600 and $1800 \mathrm{~h}$. All mice were monitored daily. Groups of 4-week-old mice were injected with $400 \mu \mathrm{g}$ polyinosinic-polycytidylic acid (pIpC; Sigma, St Louis, MO). Blood was taken weekly and analyzed with a hematology analyzer KX-21 (Sysmex Europe, Norderstedt, Hamburg, Germany). Three weeks after injection, groups of mice were sacrificed and their tissues were harvested for further analysis. Mice were euthanized by cervical dislocation after carbon dioxide inhalation. In addition, groups of mice were kept for a survival study. If mice had ruffled fur and become listless 

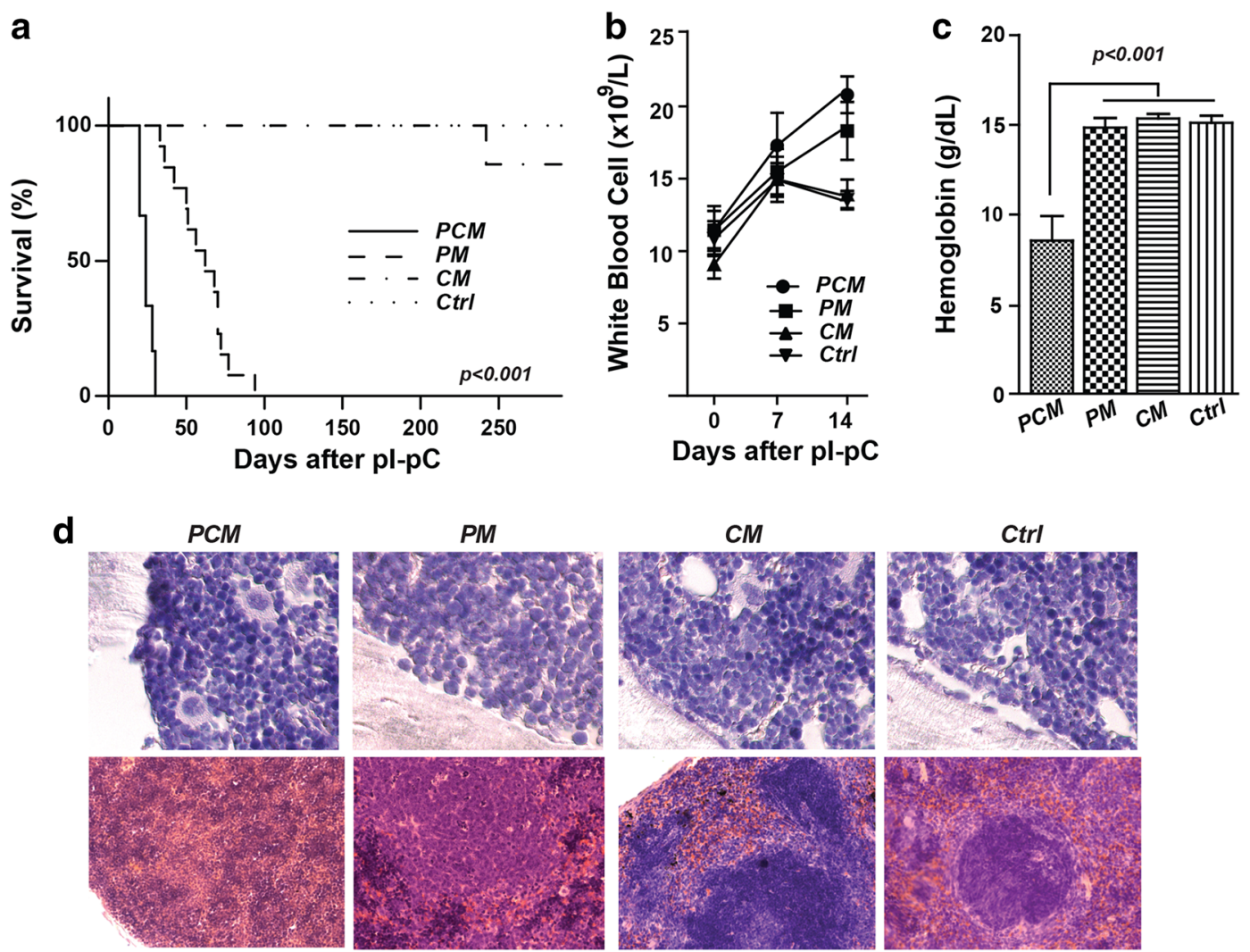

Fig. 1 Survival, white blood cell counts, hemoglobin level, and histological analysis of all groups of mice. a Kaplan-Meier survival plots for PCM $(n=6), P M(n=12), C M(n=12)$ and $C t r /$ mice $(n=12)$. b White blood cell counts of PCM, PM, CM and Ctrl mice ( $n=8$ in each group). Blood was analyzed before and 1 and 2 weeks after pl-pC injections. c Blood hemoglobin concentrations of mice at 3 weeks after pl-pC injections. d Photographs of bone marrow (top panels) and spleen (bottom panels) sections (hematoxylin and eosin staining). Magnification was $\times 100 / 1.40$ for bone marrow, $\times 20 / 0.50$ for spleens

or lost more than $10 \%$ of their body weight, they were euthanized. All experimental protocols were approved by the regional ethical committee of the University of Gothenburg, Sweden.

\section{Genotyping}

Genotyping was performed by PCR amplification of genomic DNA extracted from mouse tails. The Pten ${ }^{\mathrm{fl}}$ allele was detected with forward primer $5^{\prime}$-CAAG CACTCTGCGAACTGAG-3 ${ }^{\prime}$ and reverse primer $5^{\prime}$-AA GTTTTTGAAGGCAAGATGC-3', yielding a 328-bp fragment from the Pten ${ }^{\mathrm{fl}}$ allele and a 156-bp fragment from the $\mathrm{Pten}^{+}$allele. The $P 27^{\mathrm{fl}}$ allele was detected with forward primer 5'-TAGGGGAAAT GGATAGTAGATGTTAGGACC- $3^{\prime}$ and reverse primer 5' - G GTATAATATGGAAAGTGACTCTAATGG CC- $3^{\prime}$, yielding a 400-bp fragment from the $P 27^{\mathrm{fl}}$ allele and a 370-bp fragment from the $P 27^{+}$allele. The Mx1Cre transgene was detected with forward primer
5'-GCGGTCTGGCAGTAAAAACTATC-3' (oIMR 1084) and reverse primer 5'-GTGAAACAGCATTGCTGTC ACTT-3' (oIMR 1085) to yield a $100 \mathrm{bp}$ fragment.

\section{Fluorescence-activated cell sorting, colony assays, and histology}

Splenocytes and bone marrow cells were incubated with antibodies against Gr1 (PE-Cy7/RB6-8C5), CD11b (V450/M1/70), c-kit (PE/2B8), Sca1 (PE-Cy7/D7), Lin(FITC) and CD45 (V500/30-F11) and analyzed with FACS Diva software (BD Biosciences, San Jose, CA, USA). For colony assays, splenocytes $\left(1 \times 10^{5}\right)$ and bone marrow cells $\left(2 \times 10^{4}\right)$ harvested from experimental mice were seeded in duplicate wells in methylcellulose medium (MethoCult M3434; StemCell Technologies, Vancouver, BC, Canada). Six days later, the numbers of colonies were scored. For bone marrow cells, on the 7th day the cultured cells were washed, collected, and replated. Histology was performed as described [19, 20]. 

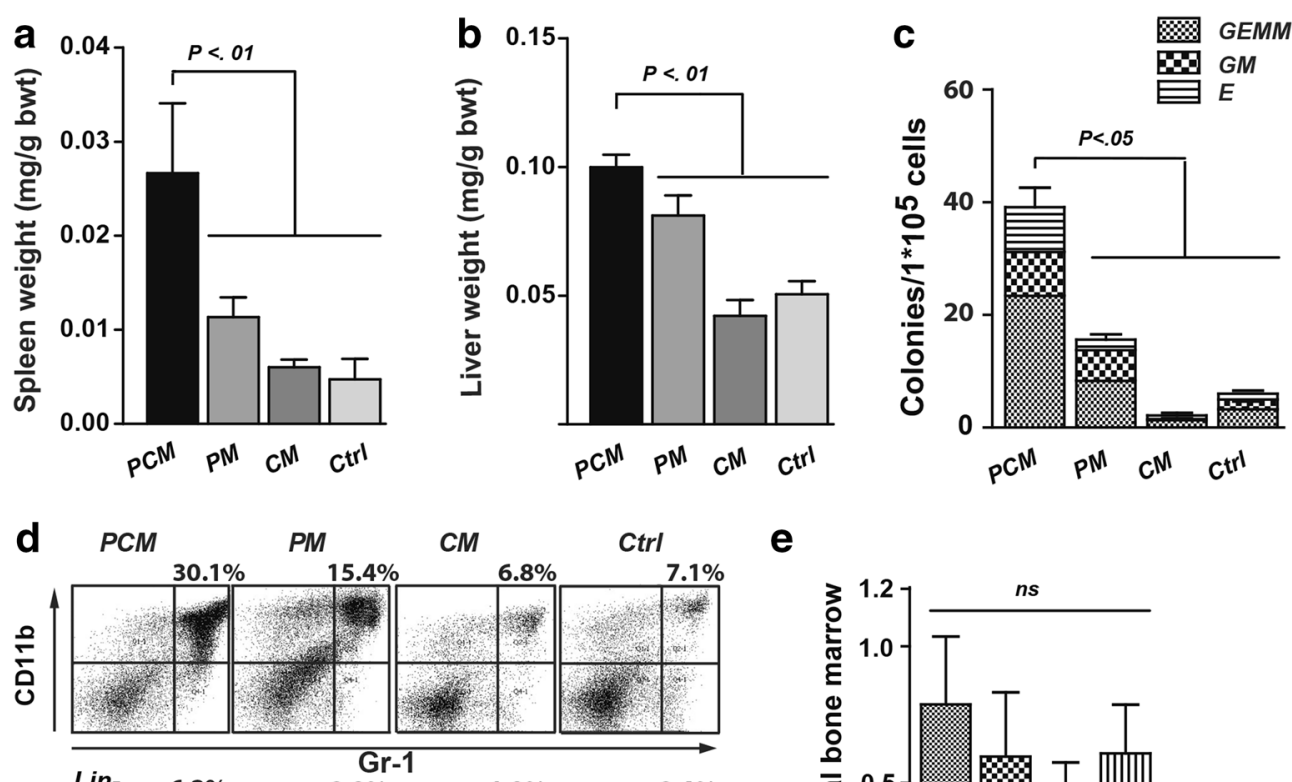

e
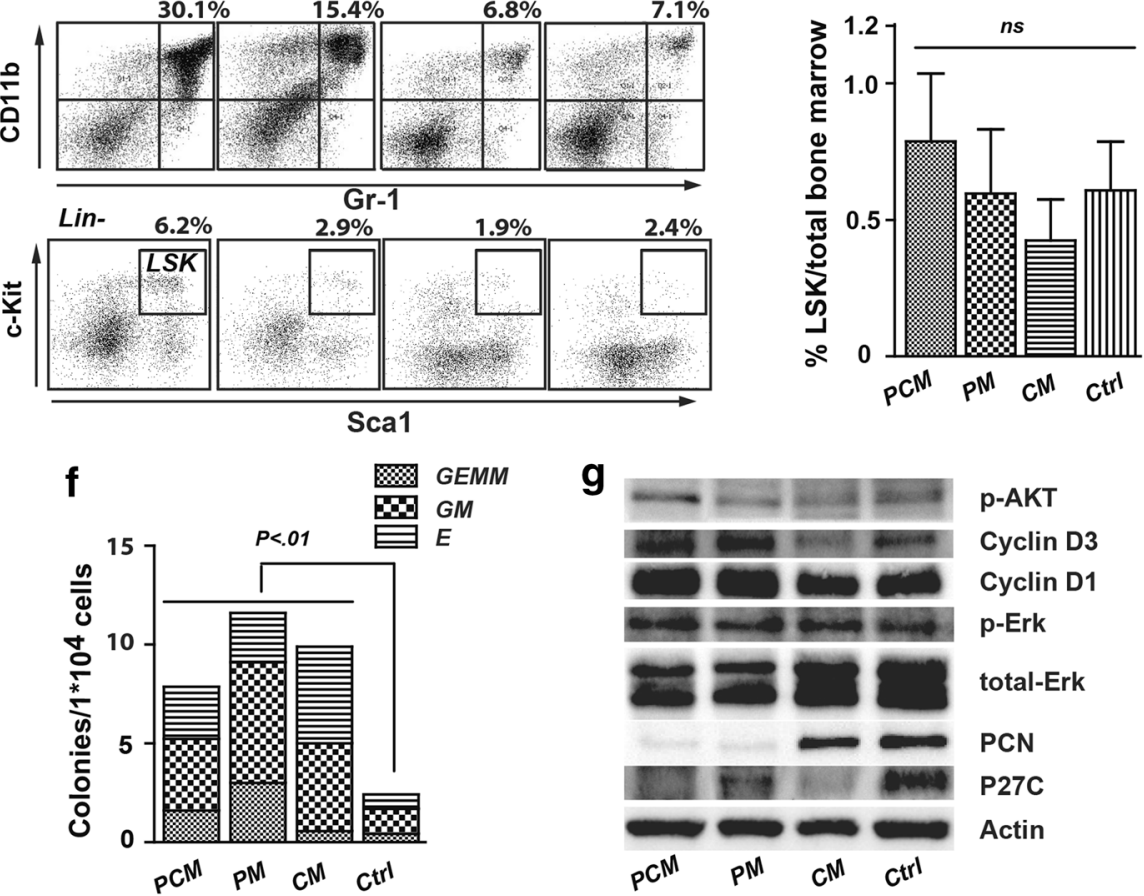

Fig. 2 PCM mice exhibit massive hepatosplenomegaly, extramedullary hematopoiesis, and increased colony growth of splenocytes. a Spleen and b liver weight [relative to total body weight (bwt)] in PCM $(n=5), P M(n=5), C M(n=5)$, and $C t r l(n=5)$ mice 3 weeks after pl-pC injections. c Colony-forming ability of splenocytes isolated from PCM $(n=3), P M(n=3), C M(n=3)$ and $C \operatorname{trl}(n=3)$ mice around 3 weeks after pl-pC injections. GEMM colony-forming unit-granulocyte, erythroid, macrophage, megakaryocyte, GM colony-forming unit-granulocyte, macrophage, E burst-forming unit-erythroid. d Representative flow cytometry plots of splenocytes with antibodies recognizing CD11b, Gr-1, c-Kit, Sca1 and Lineage-negative. The mean percentage of double-positive splenocytes from PCM $(n=3), P M(n=3), C M(n=3)$, and $C t r l(n=3)$ mice is indicated. e Percentage of LSK cells in bone marrow from PCM $(n=3), P M(n=3), C M(n=3)$, and $C \operatorname{trl}(n=3)$ mice, as determined with flow cytometry. f Colony-forming ability of bone marrow from $P C M(n=3), P M(n=3), C M(n=3)$, and $C t r l(n=3)$ mice. $g$ Western blots of protein extracts from splenocytes of $P C M(n=2), P M(n=2), C M(n=2)$, and $C t r l(n=2)$ mice at the 3rd week after pl-pC injection. Actin was used as the loading control

\section{Western blots}

Tissue pieces (50-100 mg) were lysed in ice-cold buffer (50 mM Tris- $\mathrm{HCl}, 120 \mathrm{mM} \mathrm{NaCl}, 5 \mathrm{mM} \mathrm{MgCl}_{2}, 1 \%$ Triton X-100, $0.1 \%$ sodium dodecyl sulfate, $1 \%$ NP-40, $20 \mathrm{mM} \mathrm{NaF}, 1 \mathrm{mM}$ phenylmethylsulfonyl fluoride, $2 \mathrm{mM}$ orthovanadate, and the Complete Mini protease inhibitor cocktail). Lysates were homogenized, and centrifuged at
$20,000 \mathrm{~g}$ for $20 \mathrm{~min}$, and equal amounts of total protein of the supernatant were size-fractionated on 10-15\% sodium dodecyl sulfate polyacrylamide gels. The proteins were transferred onto nitrocellulose membranes and incubated with antibodies against phosphorylated ERK1/2 (9106), total ERK (9102), phosphorylated AKT (9271), PTEN (9559), p27 ${ }^{\mathrm{KIP} 1}$ (2552; Cell Signaling, 
Danvers, MA), Cyclin D1(sc-718), Cyclin D3 (sc-182), and Beta-actin (sc-47778; Santa Cruz Biotechnology, Inc., Dallas, TX). Protein bands were visualized with a horseradish peroxidase-conjugated secondary antibody (1705046 and 170-5047; Bio-Rad Laboratories, Inc., Hercules, California) and the Enhanced Chemiluminescence Kit (Amersham, Little Chalfont, Buckinghamshire, United Kingdom). Band density was measured by Quantity One software (Bio-Rad Laboratories, Inc. USA).

\section{Statistical analyses}

Data are plotted as the mean \pm SEM. Differences in the concentrations and percentages of white blood cells, the colony-forming ability of hematopoietic cells, and the proliferation of cells in culture were determined with Student's $t$ test. Differences in mouse survival were assessed by the Mann-Whitney $U$ test.

\begin{abstract}
Abbreviations
PTEN: phosphatase and tensin homolog; CDKN1B: cyclin-dependent kinase inhibitor 1B; PI3K: phosphatidylinositol-4,5-bisphosphate 3-kinase; AKT(PKB): protein kinase B; PIP3: phosphatidylinositol-3,4,5-trisphosphate; MPN: myeloproliferative neoplasm; pl-pC: polyinosinic-polycytidylic; PCM: Pten ${ }^{\text {f/fl }}$ Cdkn1 $b^{f / f l}$ Mx1-Cre; PM: Pten ${ }^{f / f l}$ Mx1-Cre; CM: Cdkn1 1f/fl Mx1-Cre; Ctrl: Control; LSK: lineage-negative (lin-), Sca-1+, c-Kit+; ERK: extracellular signal-regulated kinase; mTOR: mechanistic target of rapamycin; JAK2: Janus kinase 2; SEM: standard error of the mean.
\end{abstract}

\section{Authors' contributions}

IS designed and carried out experimental work and wrote the manuscript. VML designed the work and wrote the manuscript. SL carried out experimental work and analysis of data. KB carried out the acquisition and analysis of data. SYW, KL analysed the data and revised the manuscript. All authors read and approved the final manuscript.

\section{Author details}

${ }^{1}$ Department of Clinical Chemistry and Transfusion Medicine, Institute of Biomedicine, Sahlgrenska Academy, University of Gothenburg, Gothenburg, Sweden. ${ }^{2}$ Laboratory of Clinical Chemistry, Sahlgrenska University Hospital, Gothenburg, Sweden. ${ }^{3}$ Section for Haematology and Coagulation, Department of Medicine, Sahlgrenska University Hospital, Gothenburg, Sweden. ${ }^{4}$ Department of Chemistry and Molecular Biology, University of Gothenburg, Gothenburg, Sweden.

\section{Acknowledgements}

We thank Matthew Fero from Cancer Research Center, Seattle, USA for kindly providing the mouse models.

\section{Competing interests}

The authors declare that they have no competing interests.

\section{Availability of data and materials}

Not applicable.

\section{Consent for publication}

Not applicable.

\section{Ethics approval and consent to participate}

All animal experimental protocols were approved by the regional ethical committee of the University of Gothenburg, Sweden.

\section{Funding}

This study was supported by Stiftelsen Assar Gabrielssons Fond (FB14-18), internal university funding from Gothenburg University and Sahlgrenska University Hospital (to V.M.L).

Received: 26 April 2016 Accepted: 10 June 2016

Published online: 30 June 2016

\section{References}

1. Liu YL, Castleberry RP, Emanuel PD. PTEN deficiency is a common defect in juvenile myelomonocytic leukemia. Leuk Res. 2009;33:671-7.

2. Gutierrez A, Sanda T, Grebliunaite R, Carracedo A, Salmena L, Ahn Y, et al. High frequency of PTEN, PI3K and AKT abnormalities in T-cell acute lymphoblastic leukemia. Blood. 2009;114:647-50.

3. Rossi DJ, Weissman IL. Pten, tumorigenesis, and stem cell self-renewal. Cell. 2006;125:229-31.

4. Chu IM, Hengst L, Slingerland JM. The Cdk inhibitor p27 in human cancer: prognostic potential and relevance to anticancer therapy. Nat Rev Cancer. 2008;8:253-67.

5. Komuro H, Valentine MB, Rubnitz JE, Saito M, Raimondi SC, Carroll AJ, et al. p27KIP1 deletions in childhood acute lymphoblastic leukemia. Neoplasia. 1999;1:253-61.

6. Haferlach C, Bacher U, Kohlmann A, Schindela S, Alpermann T, Kern W, et al. CDKN1B, encoding the cyclin-dependent kinase inhibitor 1B (p27), is located in the minimally deleted region of $12 \mathrm{p}$ abnormalities in myeloid malignancies and its low expression is a favorable prognostic marker in acute myeloid leukemia. Haematologica. 2011;96:829-36.

7. Dietrich S, Hullein J, Lee SC, Hutter B, Gonzalez D, Jayne S, et al. Recurrent CDKN1B (p27) mutations in hairy cell leukemia. Blood. 2015;126:1005-8.

8. Di Cristofano A, De Acetis M, Koff A, Cordon-Cardo C, Pandolfi PP. Pten and p27KIP1 cooperate in prostate cancer tumor suppression in the mouse. Nat Genet. 2001;27:222-4.

9. Uner AH, Saglam A, Han U, Hayran M, Sungur A, Ruacan S. PTEN and p27 expression in mature T-cell and NK-cell neoplasms. Leuk Lymphoma. 2005:46:1463-70.

10. Halvorsen OJ, Haukaas SA, Akslen LA. Combined loss of PTEN and p27 expression is associated with tumor cell proliferation by $\mathrm{Ki}-67$ and increased risk of recurrent disease in localized prostate cancer. Clin Cancer Res. 2003;9:1474-9.

11. Fero ML, Rivkin M, Tasch M, Porter P, Carow CE, Firpo E, et al. A syndrome of multiorgan hyperplasia with features of gigantism, tumorigenesis, and female sterility in p27(Kip1)-deficient mice. Cell. 1996;85:733-44.

12. Guo W, Lasky JL, Chang CJ, Mosessian S, Lewis X, Xiao Y, et al. Multigenetic events collaboratively contribute to Pten-null leukaemia stemcell formation. Nature. 2008;453:529-33.

13. Wey S, Luo B, Tseng CC, Ni M, Zhou H, Fu Y, et al. Inducible knockout of GRP78/BiP in the hematopoietic system suppresses Pten-null leukemogenesis and AKT oncogenic signaling. Blood. 2012;119:817-25.

14. Kogan SC, Ward JM, Anver MR, Berman JJ, Brayton C, Cardiff RD, et al. Bethesda proposals for classification of nonlymphoid hematopoietic neoplasms in mice. Blood. 2002;100:238-45.

15. Sun H, Lesche R, Li DM, Liliental J, Zhang H, Gao J, et al. PTEN modulates cell cycle progression and cell survival by regulating phosphatidylinositol 3,4,5,-trisphosphate and Akt/protein kinase B signaling pathway. Proc Natl Acad Sci USA. 1999:96:6199-204.

16. Kurose K, Zhou XP, Araki T, Cannistra SA, Maher ER, Eng C. Frequent loss of PTEN expression is linked to elevated phosphorylated Akt levels, but not associated with p27 and cyclin D1 expression, in primary epithelial ovarian carcinomas. Am J Pathol. 2001;158:2097-106.

17. Bartalucci N, Tozzi L, Bogani C, Martinelli S, Rotunno G, Villeval JL, et al. Co-targeting the PI3K/mTOR and JAK2 signalling pathways produces synergistic activity against myeloproliferative neoplasms. J Cell Mol Med. 2013;17:1385-96. 
18. Nagai Y, Kawahara M, Sugino N, Shimazu Y, Hishizawa M, Yamashita K, et al. A case of minor BCR-ABL1 positive acute lymphoblastic leukemia following essential thrombocythemia and originating from a clone distinct from that harboring the JAK2-V617F mutation. Exp Hematol Oncol. 2014;3:6.

19. Reddy P, Liu L, Adhikari D, Jagarlamudi K, Rajareddy S, Shen Y, et al. Oocyte-specific deletion of Pten causes premature activation of the primordial follicle pool. Science. 2008;319:611-3.
20. Rajareddy S, Reddy P, Du C, Liu L, Jagarlamudi K, Tang W, et al. p27kip1 (cyclin-dependent kinase inhibitor 1B) controls ovarian development by suppressing follicle endowment and activation and promoting follicle atresia in mice. Mol Endocrinol. 2007;21:2189-202.

\section{Submit your next manuscript to BioMed Central and we will help you at every step:}

- We accept pre-submission inquiries

- Our selector tool helps you to find the most relevant journal

- We provide round the clock customer support

- Convenient online submission

- Thorough peer review

- Inclusion in PubMed and all major indexing services

- Maximum visibility for your research

Submit your manuscript at

www.biomedcentral com/submit 